Published in final edited form as:

J Acquir Immune Defic Syndr. 2015 January 1; 68(1): 97-101. doi:10.1097/QAI.0000000000000403.

\title{
Longitudinal trends in HIV non-occupational post-exposure prophylaxis (NPEP) use at a Boston community health center between 1997 and 2013
}

\author{
Sachin Jain, MD MPH ${ }^{1,2,4}$, Catherine E. Oldenburg, MPH $^{2,3}$, Matthew J. Mimiaga, MPH, \\ ScD ${ }^{2,3,4,5}$, and Kenneth H. Mayer, MD ${ }^{1,2,4}$ \\ ${ }^{1}$ Beth Israel Deaconess Medical Center, Division of Infectious Diseases, Boston, United States \\ ${ }^{2}$ The Fenway Institute, Boston, United States \\ ${ }^{3}$ Harvard School of Public Health, Department of Epidemiology, Boston, United States \\ ${ }^{4}$ Harvard Medical School, Boston, United States \\ ${ }^{5}$ Massachusetts General Hospital, Department of Psychiatry, Boston, United States
}

\begin{abstract}
Secular trends in non-occupational post-exposure prophylaxis (NPEP) use have not been wellcharacterized. We performed a retrospective longitudinal study of 894 electronic medical records of NPEP users, mostly men who have sex with men, at a Boston community health center who presented between July, 1997 and August, 2013. NPEP use and condomless sexual exposures increased over time; 19.4\% had multiple NPEP courses. Having an HIV-infected partner was associated with increased odds of regimen completion, and three-drug regimens were associated with decreased odds of completion. Targeted adherence and risk-reduction counseling are warranted for select NPEP users at this center.
\end{abstract}

\section{Keywords}

PEP; NPEP; post exposure prophylaxis; HIV; biomedical prevention

\section{INTRODUCTION}

Despite an increasing number of interventions to prevent HIV transmission, ${ }^{1-7}$ approximately 50,000 new HIV infections occur in the United States each year, ${ }^{8} \mathrm{HIV}$ nonoccupational post-exposure prophylaxis (NPEP) entails a 28-day course of antiretroviral medication administered to HIV-uninfected individuals within 72 hours after a potential sexual or intravenous drug needle exposure to HIV, which the CDC has recommended by since 2005. ${ }^{9}$ Although NPEP efficacy trials have not been performed, its effectiveness is

Corresponding Author: Sachin Jain, MD MPH, Beth Israel Deaconess Medical Center, Division of Infectious Diseases, 110 Francis Street, LMOB Ground Floor, Boston, MA 02215, sjain4@bidmc.harvard.edu, Phone: 847-567-9100, Fax: 617-632-7626.

Conflicts of Interest

For the remaining authors none were declared. 
supported by macaque models ${ }^{10-11}$ and a large retrospective case-control study of occupational PEP. ${ }^{12}$

While the frequency of unprotected anal intercourse increased from $48 \%$ to $57 \%$ from 2005 to 2011 in men who have sex with men (MSM) who are HIV-uninfected or had unknown status, ${ }^{13}$ several studies have reported that awareness of NPEP among high-risk MSM has remained low. ${ }^{14-19}$ In addition, subsequent HIV acquisition rates have been high among MSM PEP users in several series. ${ }^{15,20-23}$ Multiple centers have reported that newer PEP regimens have improved tolerability and fewer drug-drug interactions ${ }^{24-28}$ compared to earlier regimens. ${ }^{29-31}$ However, the factors associated with NPEP completion and noncompletion have not been well-described, as few studies have examined long-term trends of NPEP use within the past 10 years. ${ }^{15,23,32-33}$ In order to understand the specific behaviors, patterns, and outcomes of NPEP users to guide future prevention interventions, we examined the characteristics of NPEP users and circumstances of exposures, frequency of NPEP use, and trends in prescriptions and tolerability of NPEP regimens among persons who used NPEP since 1997 at the largest NPEP provider in New England.

\section{METHODS}

\section{Patients and Procedures}

This study is a retrospective longitudinal review of NPEP users at a large urban community health center in Boston, MA, who presented between July 1, 1997 and August 1, 2013. Any HIV-negative patient who had a prescription for antiretroviral medication in their electronic medical record during this time period was screened for study eligibility. Inclusion criteria included: 1) age 18 years or older at NPEP enrollment; 2) sexual or intravenous drug needle exposure; and 3) negative baseline HIV test at the time of NPEP presentation. Patients were excluded if they had confirmatory positive HIV testing within 30 days of antiretroviral treatment, were prescribed NPEP after reporting an exposure by phone but did not follow up in person, were prescribed antiretrovirals for anything other than NPEP, had occupational exposures, or were enrolled in an NPEP clinical trial.

Extracted demographic information for each NPEP course included: date of birth, date of initial encounter at the health center, date of last encounter or HIV test, gender identity, race, gender preferences of sexual partner, and insurance status. Each patient could have had multiple NPEP courses over the study period. The following data were extracted: date of NPEP enrollment, nature of exposure, and partner's reported HIV status. Providers used a standardized intake form containing this information. Prescribed antiretroviral regimen, regimen completion, reasons for documented non-completion or modifying the regimen, adverse effects, and follow-up at 1,3, and 6 month intervals after the exposure were recorded. Any HIV testing, including a rapid whole blood fingerstick assay or a serum antibody and/or plasma viral load, was required to count as having followed up at 3 and 6 months. Each provider chose the NPEP regimen on a case-by-case basis after a rapid HIV test was confirmed to be negative and did not follow a specific center-specific protocol. 


\section{Statistical Methods}

Proportions for categorical variables and means and standard deviations for continuous variables were calculated for descriptive characteristics of the sample. NPEP regimens were tabulated by specific drug regimen, and comparisons were made between 2 versus 3-drug regimens, and azidothymidine-versus tenofovir-based regimens. Logistic generalized estimation equation (GEE) models were used to assess trends in NPEP prescriptions over time, including reason for seeking NPEP (i.e. condomless versus protected consensual exposure with condom failure) and drug regimen (i.e. tenofovir- versus azidothymidinebased regimen). Time was modeled as a continuous variable by calendar year of NPEP prescription.

To account for the fact that patients could have multiple PEP courses, bivariate and multivariable logistic GEE models were used to assess factors associated with completing NPEP regimen. Factors included age, race/ethnicity, gender identity (categorized as MSM versus other identity for modeling purposes due to small numbers of individuals reporting non-MSM identities), insurance versus no insurance, consensual versus non-consensual exposure, partner HIV status, three-drug versus two-drug regimen, and tenofovir versus azidothymidine-based NPEP regimen. Completion analyses were restricted to patients who had documentation of regimen completion or non-completion. All analyses were conducted in Stata version 12.1 (StataCorp, College Station, TX). All study procedures were approved by the Fenway Health Institutional Review Board.

\section{RESULTS}

Of 1084 unique medical records initially identified, 894 patients prescribed 1,244 NPEP courses met the inclusion criteria. Of the 894 patients, 19.4\% presented for NPEP multiple times (range 2 to 15, mean:1.4; median:1, IQR:1 to 1). Most common reasons for 190 patients being excluded from the study were: no documentation of PEP corresponding to date of antiretroviral prescription (21.1\%), antiretrovirals prescribed for pre-exposure prophylaxis (PrEP) (21.6\%) or Hepatitis B (11.1\%), patient requested a privacy alert that requires any provider to enter a medical reason before accessing their record $(21.6 \%)$, and occupational exposures $(12.6 \%)$.

Of the 894 patients in this analysis, median age at first NPEP course was 32.3 years (IQR: 26.3 to 40.2 ; Table 1). Most (88.1\%) were MSM, 56.2\% had private insurance, and $71.5 \%$ were non-Latino white. Reasons for seeking NPEP included consensual condomless sex (61.3\%), condom failure/removal (31.4\%), non-consensual sex (5.3\%), and injection drug use $(1.1 \%$; Table 1$)$.

Consensual condomless exposures included receptive oral (21.3\%), insertive anal (36.6\%), receptive anal (56.6\%), insertive vaginal (1.2\%), and receptive vaginal sex (2.5\%). Patients may have reported more than one exposure at a given NPEP visit. The HIV serostatus of the partner was unknown for $62.1 \%$. Among those who reported a known HIV-infected source, the treatment status was unknown for $17.2 \%, 4.1 \%$ thought the source was not on treatment, and $13 \%$ thought the source was on treatment. Among consensual sexual exposures, the 
proportion of reported condomless exposures increased by year ( $\mathrm{OR}=1.05$ per year, $95 \% \mathrm{CI}$ : $1.01-1.08, \mathrm{P}=0.004)$.

Consensual sexual exposure in which there was a condom failure occurred in $29.9 \%$ of NPEP courses. Among these exposures, $67.7 \%$ were with partners of unknown HIV status, 13.7\% known HIV-infected but unknown treatment status, 3.8\% known HIV-infected and not on treatment, and $14.8 \%$ known HIV-infected and on treatment.

Non-consensual exposures included receptive oral (7.8\%), insertive anal (3.0\%), receptive anal $(56.1 \%)$, and receptive vaginal sex (43.9\%). Most (92.4\%) partners were of unknown HIV status; $6.1 \%$ were known HIV-infected but treatment status unknown, and $1.5 \%$ were known HIV-infected and known to be on treatment. Fourteen (1.1\%) patients presented for NPEP due to recreational injection drug exposure.

Figure 1A shows the distribution of NPEP prescriptions by year. Overall there was an increasing trend in number of NPEP prescriptions per year. The most commonly-prescribed regimens contained tenofovir, which began in 2005 and increased over time $(P<0.001)$.

Nearly half (47.6\%) of regimens consisted of three drugs, and there was a decrease in threedrug regimens over time, with two-drug regimens becoming increasingly prevalent $(\mathrm{P}<0.001)$.

Among the 540 patients ( $43.4 \%$ of the sample) with documented completion status, $85.7 \%$ completed their NPEP regimen. Among the 77 (14.3\%) who did not complete their regimen, reasons included medication intolerance (48.1\%) due to nausea (43.2\%), diarrhea (13.5\%), and rash (13.5\%), and learning that one's partner was HIV-negative (9.1\%), but for almost half $(45.5 \%)$, the reasons were not specified. A substantial proportion of patients (10.5\%) did not return for any follow-up after the initial NPEP visit. Among those with documented completion status, having an HIV-infected partner (AOR 1.90, 95\%CI: 1.05-3.45, $\mathrm{P}=0.03$ ) was associated with increased odds of completion of regimen, and a three-drug regimen (versus two-drug, AOR 0.45, 95\% CI: 0.25-0.78, $\mathrm{P}=0.005$ ) was associated with decreased odds of completion. The year of NPEP enrollment (AOR 1.12; 95\%CI: 1.06-1.18; P<0.001) and tenofovir-based regimens (versus azidothymidine-based regimens; AOR 2.80; 95\%CI: $1.69-4.63 ; \mathrm{P}<0.001$ ) were strongly associated with completion in the bivariate analysis but dropped out in the multivariable analysis (Table 2).

\section{DISCUSSION}

While NPEP is generally underutilized, ${ }^{34}$ this study noted a rise in number of NPEP courses and consensual condomless sex over a 16-year period, with $56.6 \%$ of all consensual sexual exposures involving condomless anal receptive intercourse. The frequency of recurrent NPEP coincides with the 9-28\% range as reported in other settings. ${ }^{20,32,35-36}$ Our data are also consistent with other studies which demonstrated that many MSM who received NPEP continued to practice high-risk behaviors and remained at elevated risk for HIV acquisition. ${ }^{15,23}$ While NPEP users are typically self-selected patients that may be more knowledgeable about biomedical prevention, the recurrent use of NPEP for condomless anal sex represents a lack of uptake of or ineffective risk-reduction counseling provided during 
NPEP. These data suggest the need to anticipate that many NPEP users remain at increased risk for HIV acquisition after NPEP and may be good candidates for PrEP and other evidence-based biobehavioral interventions. ${ }^{37}$

Regarding NPEP prescriptions, there was a shift from azidothymidine to tenofovir-based regimens after the approval of tenofovir/emtricitabine for HIV treatment in 2004. Since then, there has been a steady rise in NPEP prescriptions at this health center using tenofovir/ emtricitabine alone or in combination with lopinavir/ritonavir, efavirenz, or raltegravir. Furthermore, tenofovir-based regimens tended to be associated with increased NPEP completion rates, which reinforces that providers should favor tenofovir-based regimens for NPEP. This finding also has important implications for pre-exposure prophylaxis (PrEP), for which the current U.S. Food and Drug Administration has approved tenofoviremtricitabine. ${ }^{38}$ Further studies are required to assess the association between NPEP completion with a tenofovir-based regimen and PrEP tolerability.

The fact that an HIV-infected partner was associated with better completion rates may reflect a higher self-perceived HIV risk compared to those who have partners with unknown status. The decreased completion while on 3-drug regimens as compared to 2-drug regimens is likely to be related to the regimen factors, namely dosing, pill burden, and adverse effects. Although it has not been feasible to do a head-to-head study of 2- versus 3-drug regimens, a decision analysis by Bassett and colleagues suggested that a 2-drug regimen might be preferable because better tolerability might lead to increased completion rates. ${ }^{39}$ However, newer regimens containing tenofovir and using integrase inhibitors may enable patients assigned to a 3-drug regimen to experience fewer side effects and lower pill burdens compared to earlier regimens that relied on azidothymidine-based combinations and ritonavir-boosted protease inhibitors.

This study has several limitations, particularly the retrospective design. Adverse effects and completion of NPEP regimens were inconsistently reported, including circumstances when patients returned for follow-up at the appropriate interval. Documentation of regimen completion was unavailable for $56.6 \%$ of NPEP courses, and nearly $20 \%$ of patients did not follow up after completion of their regimen. Whether these patients differed substantially from those who returned for follow-up is unknown.

There may have been outstanding factors that influenced the selection of NPEP regimens, such as co-morbid conditions, duration and aggressiveness of sexual contact, report of visible blood at the site of exposure, and whether or not the insertive source partner ejaculated inside the exposed patient. While victims of sexual assault represented a small proportion of this sample, it is possible that many sought NPEP at local emergency departments, which may explain the predominance of consensual exposures here.

This study demonstrates that NPEP is an increasingly utilized method of biomedical prevention of HIV at this large urban community health center and that NPEP users demonstrated recurrent high-risk behavior. These findings reinforce that earlier, targeted HIV risk-reduction and PrEP counseling may be warranted for a select group of NPEP users. It will also be critical to engage groups such as high-risk MSM of color, who are 
underrepresented in this study and are likely to be underutilizing NPEP, despite being disproportionately affected by HIV.

\section{ACKNOWLEDGEMENTS}

The Fenway Institute Data Team, including Chris Grasso MPH, Ken Levine, and Shayne Zaslow, screened eligible patients for this study, aided with construction of the data abstraction tool, and provided database support. The Harvard University Center For AIDS Research (CFAR), an NIH funded program (P30 AI060354; PI: Walker), provided statistical consultation.

Source of Funding: Oldenburg is supported by a National Institute of Allergy and Infectious Disease T32 NRSA grant (T32AI007535; PI: Seage) and a National Institute of Drug Abuse T32 NRSA grant (T32DA0131911; PI: Flanigan). Mayer receives funding from the Harvard University Center For AIDS Research (CFAR), an NIH funded program (P30 AI060354; PI: Walker).

\section{REFERENCES}

1. Cohen MS, Chen YQ, McCauley M, et al. Prevention of HIV-1 infection with early antiretroviral therapy. N Engl J Med. Aug 11; 2011 365(6):493-505. [PubMed: 21767103]

2. Grant RM, Lama JR, Anderson PL, et al. Preexposure chemoprophylaxis for HIV prevention in men who have sex with men. N Engl J Med. Dec 30; 2010 363(27):2587-99. [PubMed: 21091279]

3. Baeten JM, Donnell D, Ndase P, et al. Antiretroviral prophylaxis for HIV prevention in heterosexual men and women. N Engl J Med. Aug 2; 2012 367(5):399-410. [PubMed: 22784037]

4. Thigpen MC, Kebaabetswe PM, Paxton LA, et al. Antiretroviral preexposure prophylaxis for heterosexual HIV transmission in Botswana. N Engl J Med. Aug 2; 2012 367(5):423-34. [PubMed: 22784038]

5. Auvert B, Taljaard D, Lagarde E, et al. Randomized, controlled intervention trial of male circumcision for reduction of HIV infection risk: the ANRS 1265 trial. PLoS Med. 2005; 2(11):e298. [PubMed: 16231970]

6. Gray RH, Kigozi G, Serwadda D, et al. Male circumcision for HIV prevention in men in Rakai, Uganda: a randomized trial. Lancet. 2007; 369:657-666. [PubMed: 17321311]

7. Bailey RC, Moses S, Parker CB, et al. Male circumcision for HIV prevention in young men in Kisumu, Kenya: a randomised controlled trial. Lancet. 2007; 369:643-656. [PubMed: 17321310]

8. Prejean J, Song R, Hernandez A, et al. Estimated HIV incidence in the United States, 2006-2009. PLoS ONE. 2011; 6:e17502. [PubMed: 21826193]

9. Smith DK, Grohskopf LA, Black RJ, et al. Antiretroviral postexposure prophylaxis after sexual, injection-drug use, or other nonoccupational exposure to HIV in the United States: recommendations from the US Department of Health and Human Services. MMWR Recomm Rep. 2005; 54(RR-2):1-19. [PubMed: 15660015]

10. Tsai CC, Follis KE, Sabo A, et al. Prevention of SIV infection in macaques by (R)-9-(2phosphonylmethoxypropyl)adenine. Science. Nov 17; 1995 270(5239):1197-9. [PubMed: 7502044]

11. Otten RA, Smith DK, Adams DR, et al. Efficacy of postexposure prophylaxis after intravaginal exposure of pig-tailed macaques to a human-derived retrovirus (human immunodeficiency virus type 2). J Virol. 2000; 74(20):9771-5. [PubMed: 11000253]

12. Cardo DM, Culver DH, Ciesielski CA, et al. A case-control study of HIV seroconversion in health care workers after percutaneous exposure. Centers for Disease Control and Prevention Needlestick Surveillance Group. N Engl J Med. Nov 20; 1997 337(21):1485-90. [PubMed: 9366579]

13. CDC. HIV Testing and Risk Behaviors Among Gay, Bisexual, and Other Men Who Have Sex with Men - United States. MMWR Morb Mortal Wkly Rep. Nov 29; 2013 62(47):958-62. [PubMed: 24280915]

14. Mimiaga MJ, Case P, Johnson CV, et al. Preexposure antiretroviral prophylaxis attitudes in highrisk Boston area men who report having sex with men: limited knowledge and experience but potential for increased utilization after education. J Acquir Immune Defic Syndr. Jan 1; 2009 50(1):77-83. [PubMed: 19295337] 
15. Poynten IM, Jin F, Mao L, et al. Nonoccupational postexposure prophylaxis, subsequent risk behaviour and HIV incidence in a cohort of Australian homosexual men. AIDS. Jun 1; 2009 23(9): 1119-26. [PubMed: 19417578]

16. Donnell D, Mimiaga MJ, Mayer K, Chesney M, Koblin B, Coates T. Use of non-occupational post-exposure prophylaxis does not lead to an increase in high risk sex behaviors in men who have sex with men participating in the EXPLORE trial. AIDS Behav. Oct; 2010 14(5):1182-9. [PubMed: 20490908]

17. Mehta SA, Silvera R, Bernstein K, Holzman RS, Aberg JA, Daskalakis DC. Awareness of postexposure HIV prophylaxis in high-risk men who have sex with men in New York City. Sex Transm Infect. Jun; 2011 87(4):344-8. [PubMed: 21357600]

18. Fernández-Balbuena S, Belza MJ, Castilla J, Hoyos J, Rosales-Statkus ME, Sánchez R, de la Fuente L, Madrid Rapid HIV Testing Group. Awareness and use of nonoccupational HIV postexposure prophylaxis among people receiving rapid HIV testing in Spain. HIV Med. Apr; 2013 14(4):252-7. [PubMed: 23088284]

19. Joshi M, Basra A, McCormick C, et al. Post-exposure prophylaxis after sexual exposure (PEPSE) awareness in an HIV-positive cohort. Int J STD AIDS. Jan; 2014 25(1):67-9. [PubMed: 23970629]

20. Schechter M, do Lago RF, Mendelsohn AB, et al. Behavioral impact, acceptability, and HIV incidence among homosexual men with access to postexposure chemoprophylaxis for HIV. $\mathrm{J}$ Acquir Immune Defic Syndr. Apr 15; 2004 35(5):519-25. [PubMed: 15021317]

21. Zablotska IB, Prestage G, Holt M, et al. Australian gay men who have taken nonoccupational postexposure prophylaxis for HIV are in need of effective HIV prevention methods. J Acquir Immune Defic Syndr. Dec 1; 2011 58(4):424-8. [PubMed: 21857349]

22. Pierce AB, Yohannes K, Guy R, et al. HIV seroconversions among male non-occupational postexposure prophylaxis service users: a data linkage study. Sex Health. 2011; 8:179-183. [PubMed: 21592431]

23. Heuker J, Sonder GJ, Stolte I, Geskus R, van den Hoek A. High HIV incidence among MSM prescribed postexposure prophylaxis, 2000-2009: indications for ongoing sexual risk behaviour. AIDS. Feb 20; 2012 26(4):505-12. [PubMed: 22156963]

24. Mayer KH, Mimiaga MJ, Cohen D, et al. Tenofovir DF plus lamivudine or emtricitabine for nonoccupational postexposure prophylaxis (NPEP) in a Boston Community Health Center. $\mathbf{J}$ Acquir Immune Defic Syndr. 2008; 47(4):494-9. [PubMed: 18176318]

25. Tosini W, Muller P, Prazuck T, et al. Tolerability of HIV postexposure prophylaxis with tenofovir/ emtricitabine and lopinavir/ritonavir tablet formulation. AIDS. 2010; 24(15):2375-80. [PubMed: 20729709]

26. Burty C, Prazuck T, Truchetet F, et al. Tolerability of two different combinations of antiretroviral drugs including tenofovir used in occupational and nonoccupational postexposure prophylaxis for HIV. AIDS Patient Care STDs. Jan; 2010 24(1):1-3. [PubMed: 20095911]

27. Mayer KH, Mimiaga MJ, Gelman M, et al. Raltegravir, tenofovir DF, and emtricitabine for postexposure prophylaxis to prevent the sexual transmission of HIV: safety, tolerability, and adherence. J Acquir Immune Defic Syndr. Apr 1; 2012 59(4):354-9. [PubMed: 22267017]

28. McAllister J, Read P, McNulty A, Tong WW, Ingersoll A, Carr A. Raltegravir-emtricitabinetenofovir as HIV nonoccupational post-exposure prophylaxis in men who have sex with men: safety, tolerability and adherence. HIV Med. Jan; 2014 15(1):13-22. [PubMed: 24007390]

29. Rabaud C, Burty C, Grandidier M, et al. Tolerability of postexposure prophylaxis with the combination of zidovudine-lamivudine and lopinavir-ritonavir for HIV infection. Clin Infect Dis. Jan 15; 2005 40(2):303-5. [PubMed: 15655751]

30. Burty C, Pavel S, Ghomari K, et al. Tolerability of fosamprenavir/ritonavir associated with zidovudine-lamivudine used as postexposure prophylaxis for HIV infection. J Acquir Immune Defic Syndr. Nov 1; 2008 49(3):334-6. [PubMed: 18978479]

31. Diaz-Brito V, León A, Knobel H, et al. Post-exposure prophylaxis for HIV infection: a clinical trial comparing lopinavir/ritonavir versus atazanavir each with zidovudine/lamivudine. Antivir Ther. 2012; 17(2):337-46. [PubMed: 22293542] 
32. Armishaw J, Hoy JF, Watson KM, et al. Non-occupational post-exposure prophylaxis in Victoria, Australia: responding to high rates of re-presentation and low rates of follow-up. Int J STD AIDS. Dec; 2011 22(12):714-8. [PubMed: 22174051]

33. McDougal SJ, Alexander J, Dhanireddy S, Harrington RD, Stekler JD. Non-Occupational PostExposure Prophylaxis for HIV: 10-Year Retrospective Analysis in Seattle, Washington. PLoS One. Aug 20.2014 9(8):e105030. [PubMed: 25140868]

34. Rodriguez AE, Castel AD, Parish CL, et al. HIV medical providers' perceptions of the use of antiretroviral therapy as nonoccupational postexposure prophylaxis in 2 major metropolitan areas. J Acquir Immune Defic Syndr. Nov 1; 2013 64(Suppl 1):S68-79. [PubMed: 24126450]

35. Martin JN, Roland ME, Neilands TB, et al. Use of postexposure prophylaxis against HIV infection following sexual exposure does not lead to increases in high-risk behavior. AIDS. Mar 26; 2004 18(5):787-92. [PubMed: 15075514]

36. Sonder GJ, van den Hoek A, Regez RM, et al. Trends in HIV postexposure prophylaxis prescription and compliance after sexual exposure in Amsterdam 2000-2004. Sex Transm Dis. May; 2007 34(5):288-93. [PubMed: 16980918]

37. Roland ME, Neilands TB, Krone MR, et al. A randomized noninferiority trial of standard versus enhanced risk reduction and adherence counseling for individuals receiving post-exposure prophylaxis following sexual exposures to HIV. Clin Infect Dis. 2011; 53(1):76-83. [PubMed: 21653307]

38. U.S. Food and Drug Administration. FDA Approves First Medication to Reduce HIV Risk. Jul. 2012 available at: http://www.fda.gov/ForConsumers/ConsumerUpdates/ucm311821.htm [accessed 28 Aug 2014]

39. Bassett IV, Freedberg KA, Walensky RP. Two drugs or three? Balancing efficacy, toxicity, and resistance in postexposure prophylaxis for occupational exposure to HIV. Clin Infect Dis. 2004; 39:395-401. [PubMed: 15307008] 


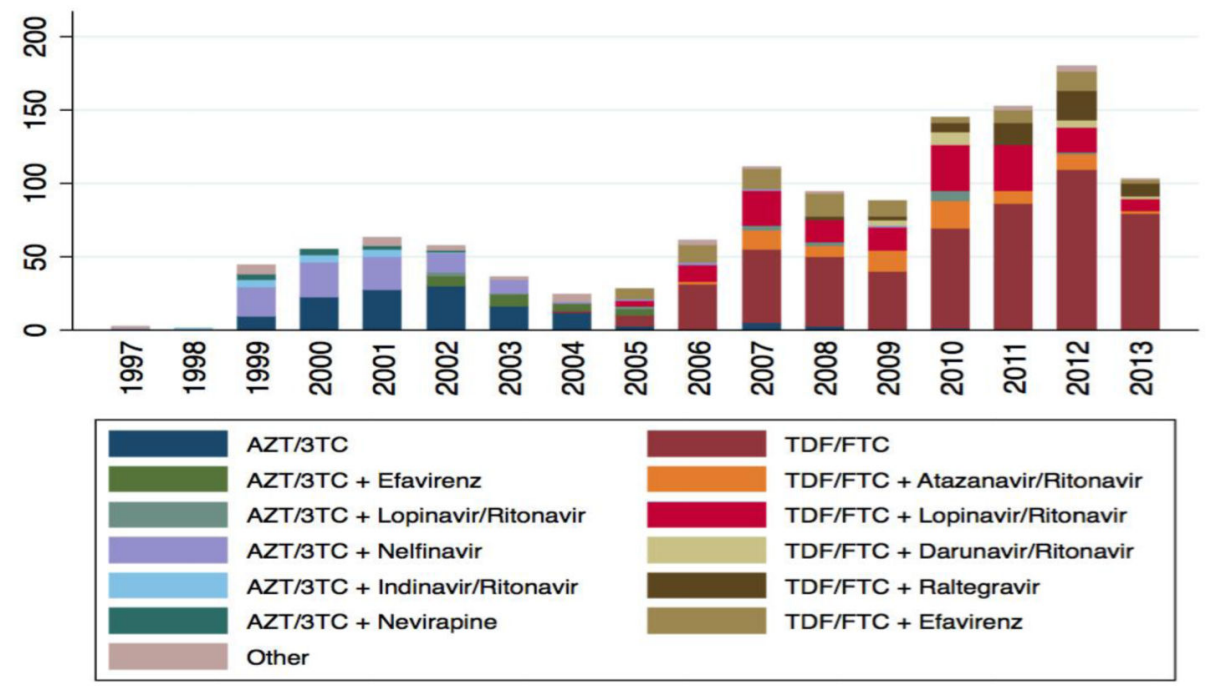

Figure 1.

NPEP trends by number of each regimen prescribed per year*

AZT: Azidothymidine; 3TC: Lamivudine; TDF: Tenofovir; FTC: Emtricitabine. Data illustrated for 2013 represents NPEP visits through August 1. Logistic generalized estimating equations were used to analyze trends over time. 
Table 1

Descriptive characteristics of individuals accessing NPEP at a large community urban health center, 1997-2013

\begin{tabular}{|c|c|}
\hline Characteristic & \\
\hline Total number of participants & 894 \\
\hline Age at NPEP enrollment, years (mean, SD) & $33.9(9.5)$ \\
\hline \multicolumn{2}{|l|}{ Gender identity } \\
\hline $\begin{array}{r}\text { MSM Male } \\
\text { MSW Male } \\
\text { Female } \\
\text { Transgender/Genderqueer }\end{array}$ & $\begin{array}{l}788(88.1 \%) \\
38(4.3 \%) \\
53(5.9 \%) \\
15(1.7 \%)\end{array}$ \\
\hline \multicolumn{2}{|l|}{ Race } \\
\hline $\begin{array}{r}\text { White } \\
\text { Latino } \\
\text { African American/Black } \\
\text { Asian } \\
\text { Other/Multiracial }\end{array}$ & $\begin{array}{c}639(71.5 \%) \\
97(10.9 \%) \\
63(7.1 \%) \\
42(4.7 \%) \\
53(5.9 \%)\end{array}$ \\
\hline \multicolumn{2}{|l|}{ Insurance Status } \\
\hline $\begin{array}{r}\text { No insurance } \\
\text { Private Insurance } \\
\text { Medicaid/Medicare/MassHealth }\end{array}$ & $\begin{array}{c}326(36.5 \%) \\
502(56.2 \%) \\
66(7.4 \%)\end{array}$ \\
\hline In primary care at health center & $553(61.9 \%)$ \\
\hline Total number of NPEP courses (range) & $1,244(1$ to 15$)$ \\
\hline \multicolumn{2}{|l|}{ Reason for NPEP enrollment } \\
\hline $\begin{array}{r}\text { Unprotected consensual sex } \\
\text { Condom failure/removal } \\
\text { Non-consensual sex/rape } \\
\text { Injection drug use }\end{array}$ & $\begin{array}{c}762(61.3 \%) \\
390(31.4 \%) \\
66(5.3 \%) \\
14(1.1 \%)\end{array}$ \\
\hline \multicolumn{2}{|l|}{ Partner HIV status } \\
\hline $\begin{array}{r}\text { Known HIV-infected - on treatment } \\
\text { Known HIV-infected - not on treatment } \\
\text { Known HIV-infected - treatment unknown } \\
\text { Unknown }\end{array}$ & $\begin{aligned} & 162(13.0 \%) \\
& 51(4.1 \%) \\
& 214(17.2 \%) \\
& 817(65.7 \%)\end{aligned}$ \\
\hline Tenofovir-based treatment regimen & $927(75.7 \%)$ \\
\hline Three-drug treatment regimen & $592(47.6 \%)$ \\
\hline
\end{tabular}

SD: standard deviation; MSM: men who have sex with men; MSW: men who have sex with women 
Table 2

Factors associated with documented completion of NPEP regimen

\begin{tabular}{|c|c|c|c|c|c|c|}
\hline Regime & completion & & & & & \\
\hline$N$ & Yes & No & $\mathrm{OR}^{1}$ & $P$ & $\mathrm{AOR}^{2}$ & $P$ \\
\hline Age, year (mean, $S D)$ & $463(85.7 \%)$ & $77(14.3 \%)$ & & & & \\
\hline MSM vs Other & $34.8(9.4)$ & $32.2(8.8)$ & 1.03 (1.01 to 1.07$)$ & 0.02 & $1.02(0.99$ to 1.06$)$ & 0.14 \\
\hline Race/Ethnicity & $427(92.2 \%)$ & $68(88.3 \%)$ & 1.55 (0.71 to 3.37$)$ & 0.20 & $1.06(0.42$ to 2.69$)$ & 0.90 \\
\hline White/Caucasian & $357(77.1 \%)$ & $55(71.4 \%)$ & Ref & $* *$ & Ref & $* *$ \\
\hline $\begin{array}{l}\text { Latino } \\
\text { Late }\end{array}$ & $46(9.9 \%)$ & $5(6.5 \%)$ & 1.38 (0.52 to 3.68$)$ & 0.52 & 1.54 (0.56 to 4.22$)$ & 0.40 \\
\hline African American & $20(4.3 \%)$ & $7(9.1 \%)$ & $0.45(0.18$ to 1.13$)$ & 0.09 & $0.43(0.16$ to 1.15$)$ & 0.09 \\
\hline Asian/Pacific Islander & $25(5.4 \%)$ & $5(6.5 \%)$ & $0.74(0.27$ to 2.06$)$ & 0.57 & $0.80(0.28$ to 2.35$)$ & 0.67 \\
\hline Other & $15(3.2 \%)$ & $5(6.5 \%)$ & $0.44(0.15$ to 1.28$)$ & 0.13 & $0.85(0.27$ to 2.72$)$ & 0.78 \\
\hline $\begin{array}{l}\text { Any insurance } \\
\text { coverage }\end{array}$ & $326(70.4 \%)$ & $50(64.9 \%)$ & 1.27 (0.76 to 2.16$)$ & 0.36 & $0.69(0.38$ to 1.25$)$ & 0.22 \\
\hline $\begin{array}{l}\text { Non-consensual } \\
\text { sexual exposure }\end{array}$ & $17(3.7 \%)$ & $5(6.5 \%)$ & $0.60(0.21$ to 1.70$)$ & 0.33 & $0.91(0.26$ to 3.19$)$ & 0.89 \\
\hline $\begin{array}{l}\text { Partner known to be } \\
\text { HIV-infected }\end{array}$ & $180(38.9 \%)$ & $22(28.6 \%)$ & $1.59(0.94$ to 2.70$)$ & 0.09 & $1.90(1.05$ to 3.45$)$ & 0.03 \\
\hline $\begin{array}{l}\text { Three-drug versus } \\
\text { two-drug regimen }\end{array}$ & $227(49.0 \%)$ & $52(67.5 \%)$ & $0.47(0.29$ to 0.79$)$ & 0.004 & 0.45 (0.25 to 0.78$)$ & 0.005 \\
\hline $\begin{array}{l}\text { Tenofovir versus } \\
\text { AZT-based regimen }\end{array}$ & $330(72.2 \%)$ & $35(47.3 \%)$ & 2.80 (1.69 to 4.63$)$ & $<0.001$ & $1.96(0.73$ to 5.28$)$ & 0.18 \\
\hline $\begin{array}{l}\text { Year of NPEP } \\
\text { enrollment (median, } \\
I Q R)\end{array}$ & $\begin{array}{c}2009 \\
(2004-2011)\end{array}$ & $\begin{array}{c}2004 \\
(2000-2011)\end{array}$ & 1.12 (1.06 to 1.18$)$ & $<0.001$ & 1.04 (0.94 to 1.16$)$ & 0.45 \\
\hline
\end{tabular}

${ }^{1}$ Odds ratio (RR) estimated with bivariate logistic generalized estimating equation (GEE) model to account for possible multiple NPEP courses per person, an odds ratio of less than 1 indicates reduced odds of non-adherence to regimen and/or follow-up visits;

${ }^{2}$ Adjusted odds ratio estimated with multivariable logistic GEE model 